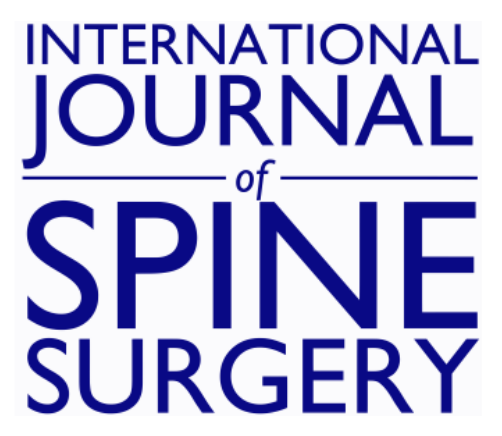

\title{
Dural Tears During Lumbar Spinal Endoscopy: Surgeon Skill, Training, Incidence, Risk Factors, and Management
}

Kai-Uwe Lewandrowski, Stefan Hellinger, Paulo Sérgio Teixeira De Carvalho, Max Rogério Freitas Ramos, José-Antonio Soriano-SáNchez, Zhang Xifeng, André Luiz Calderaro, Thiago Soares Dos Santos, Jorge Felipe Ramírez León, Marlon Sudário de Lima e SilvA, Álvaro Dowling, Girish DataR, Jin-Sung Kim and Anthony Yeung

Int J Spine Surg 2021, 15 (2) 280-294

doi: https://doi.org/10.14444/8038

http://ijssurgery.com/content/15/2/280

This information is current as of April 26, 2023.

Email Alerts Receive free email-alerts when new articles cite this article. Sign up at: http://ijssurgery.com/alerts

The International Journal of Spine Surgery 2397 Waterbury Circle, Suite 1, Aurora, IL 60504, Phone: +1-630-375-1432 


\title{
Dural Tears During Lumbar Spinal Endoscopy: Surgeon Skill, Training, Incidence, Risk Factors, and Management
}

\author{
KAI-UWE LEWANDROWSKI, MD, ${ }^{1,2}$ STEFAN HELLINGER, MD, ${ }^{3}$ PAULO SÉRGIO TEIXEIRA DE \\ CARVALHO, MD, ${ }^{4}$ MAX ROGÉRIO FREITAS RAMOS, MD, PHD,${ }^{5,6}$ JOSÉ-ANTONIO SORIANO-SÁNCHEZ, \\ MD ${ }^{7}$ ZHANG XIFENG, MD, PHD ${ }^{8}$ ANDRÉ LUIZ CALDERARO, MD,${ }^{9}$ THIAGO SOARES DOS SANTOS, \\ MD ${ }^{10}{ }^{10}$ JORGE FELIPE RAMÍREZ LEÓN, MD ${ }^{11,12}$ MARLON SUDÁRIO DE LIMA E SILVA, MD, ${ }^{13}$ ÁLVARO \\ DOWLING, MD ${ }^{14,15}$ GIRISH DATAR, MD ${ }^{16}$ JIN-SUNG KIM, MD, PHD ${ }^{17}$ ANTHONY YEUNG, MD $^{18,19}$ \\ ${ }^{I}$ Center for Advanced Spine Care of Southern Arizona and Surgical Institute of Tucson, Tucson, Arizona, ${ }^{2}$ Department of Neurosurgery, UNIRIO, Rio de Janeiro, \\ Brazil, ${ }^{3}$ Orthopaedic Surgeon, München, Germany, ${ }^{4}$ Department of Neurosurgery, Universidade Federal do Estado do Rio de Janeiro, Rio de Janeiro, Brazil, \\ ${ }^{5}$ Orthopedics and Traumatology, Federal University of the Rio de Janeiro State UNIRIO, ${ }^{6}$ Orthopedic Clinics, Gaffrée Guinle University Hospital, Universidade \\ Federal do Estado do Rio de Janeiro, Rio de Janeiro, Brazil, ${ }^{7}$ Spine Clinic, Neurological Center, ABC Medical Center, Mexico City, Mexico, ${ }^{8}$ The Chinese PLA \\ General Hospital, Beijing, China, ${ }^{9}$ Centro Ortopedico Valqueire, Departamento de Full Endoscopia da Coluna Vertebral, Rio de Janeiro, Brazil, ${ }^{10}$ Regina Hospital, \\ Novo Hamburgo, Rio Grande Sur, Brazil, ${ }^{11}$ Reina Sofia Clinic and Center of Minimally Invasive Spine Surgery, Bogotá, Colombia, ${ }^{12}$ Spine Surgery Program, \\ Universidad Sanitas, Bogotá, Colombia, ${ }^{13}$ CLINCOL (Endoscopic Spine Clinic), Belo Horizonte, Minas Gerais, Brazil, ${ }^{14}$ Endoscopic Spine Clinic, Santiago, \\ Chile, ${ }^{15}$ Department of Orthopaedic Surgery, USP, Ribeirão Preto, Brazil, ${ }^{16}$ Center for Endoscopic Spine Surgery, Sushruta Hospital for Orthopaedics and \\ Traumatology, Miraj, Sangli, Maharashtra, India, ${ }^{17}$ Seoul Saint Mary's Hospital, Seocho-gu, Seoul, Republic of Korea, ${ }^{18}$ University of New Mexico School of \\ Medicine, Albuquerque, New Mexico, ${ }^{19}$ Desert Institute for Spine Care, Phoenix, AZ
}

\begin{abstract}
Background: Incidental dural tears during lumbar endoscopy can be challenging to manage. There is limited literature on their appropriate management, risk factors, and the clinical consequences of this typically uncommon complication.

Materials and Methods: To improve the statistical power of studying durotomy with lumbar endoscopy, we performed a retrospective survey study among endoscopic spine surgeons by email and chat groups on social media networks, including WhatsApp and WeChat. Descriptive and correlative statistics were done on the surgeons' recorded responses to multiple-choice questions. Surgeons were asked about their clinical experience with spinal endoscopy, training background, the types of lumbar endoscopic decompression they perform by approach, the decompression instruments they use, and incidental durotomy incidence with routine lumbar endoscopy.

Results: There were 689 dural tears in 64470 lumbar endoscopies, resulting in an incidental durotomy incidence of $1.07 \%$. Seventy percent of the durotomies were reported by $20.4 \%$ of the surgeons. Eliminating these 19 outlier surgeons yielded an adjusted durotomy rate of 0.32 . Endoscopic stenosis decompression $(54.8 \% ; P<.0001)$, rather than endoscopic discectomy $(44.1 \%$; 41/93), was significantly more associated with durotomy. Medium-sized dural tears (1$10 \mathrm{~mm}$ ) were the most common $(52.2 \%$; 48/93). Small pinhole durotomies (less than $1 \mathrm{~mm}$ ) were the second most common type $(46.7 \% ; 43 / 93)$. Rootlet herniations were seen by $46.2 \%$ (43/93) of responding surgeons. The posterior dural sac injury during the interlaminar approach $(57 \%$; 53/93) occurred more frequently than traversing nerve-root injuries $(31.2 \%)$ or anterior dural sac $(23.7 \% ; 22 / 93)$. Exiting nerve-root injuries $(10.8 \% ; 10 / 93)$ were less common. Over half of surgeons did not attempt any repair or closure $(52.2 \% ; 47 / 90)$. Forty percent $(36 / 90)$ used sealants. Only $7.8 \%$ (7/ 90) of surgeons attempted an endoscopic repair or sutures $(11.1 \% ; 10 / 90)$. DuralSeal was the most commonly used brand of commercially available sealant used $(42.7 \% ; 35 / 82)$. However, other sealants such as Tisseal $(15.9 \% ; 13 / 82)$, Evicel $(2.4 \% 2 / 82)$, and additional no-brand sealants $(38 ; 32 / 82)$ were also used. Nearly half of the patients $(48.3 \%$; $43 /$ 89 ) were treated with $24-48$ hours of bed rest. The majority of participating surgeons $(64 \% ; 57 / 89)$ reported that the long-term outcome was unaffected. Only $18 \%$ of surgeons reported having seen the development of a postoperative cerebrospinal fluid (CSF)-fistula $(18 \% ; 16 / 89)$. However, the absolute incidence of CSF fistula was only $0.025 \%(16 /$ 64 470). Severe radiculopathy with dysesthesia; sensory loss; and motor weakness in association with an incidental durotomy were reported by $12.4 \%(11 / 89), 3.4 \%(3 / 89)$, and $2.2 \%(2 / 89)$ of surgeons, respectively.

Conclusions: The incidence of dural tears with lumbar endoscopy is about $1 \%$. The incidence of durotomy is higher with the use of power drills and the interlaminar approach. Stenosis decompression that typically requires the more aggressive use of these power instruments has a slightly higher incidence of dural tears than does endoscopic decompression for a herniated disc. Most dural tears are small and can be successfully managed with mechanical compression with Gelfoam and sealants. Two-thirds of patients with incidental dural tears had an entirely uneventful postoperative course. The remaining one-third of patients may develop a persistent CSF leak, radiculopathy with dysesthesia, sensory loss, or motor function loss. Patients should be educated preoperatively and reassured.
\end{abstract}

Level of Evidence: 3.

Minimally Invasive Surgery

Keywords: incidental durotomy, spinal endoscopy, interlaminar, transforaminal, management 


\section{INTRODUCTION}

The number of lumbar endoscopic decompression surgeries is on the rise as the procedure moves more into the mainstream and is performed not just by longtime enthusiasts but also by an increasing number of younger surgeons who can now learn the procedure in their respective postgraduate training programs. ${ }^{1,2}$ The growing number of endoscopic spine surgeries also brings a higher awareness of the procedure's complications because those numbers are on the rise as well. ${ }^{3}$ Although the overall complication rate with spinal endoscopy is relatively low and compares favorably when executed by expert surgeons, ${ }^{4}$ variations in training and skill level as well as the selection of patients for increasingly more complex clinical problems may lead to a disproportionate increase in complications. ${ }^{5}$

An unexpected dural tear is one of those accepted complications dreaded by most spine surgeons because it is technically challenging to manage through the small working channel of the endoscope, given the small size of the skin incision, ${ }^{6,7}$ working area, and the limited number of endoscopic surgical instruments available to execute a meaningful watertight repair. ${ }^{8}$ That raises the question of what to do if one encounters a dural tear during a lumbar endoscopy for herniated disc or stenosis in the foramen or lateral canal. Is a repair even necessary, or should the surgery be converted to open surgery to adequately repair the incidental durotomy? ${ }^{9} 10$ It quickly becomes apparent that there are no standardized treatment guidelines for this dreaded problem and that controversy does exist in this aspect of endoscopic spine surgery. ${ }^{11}$

One might wonder why such a consequential problem has not been studied more and why there is such a lack of literature on the subject. As of the finalizing this article, we could find only 6 articles that were entirely dedicated to the management of dural tears encountered during endoscopic spine surgery. ${ }^{7,8,11-14}$ The apparent answer likely lies in the rarity of the condition, such that it takes 1 surgeon or a group of surgeons nearly a lifetime to accumulate sufficient numbers to study the factors that influence the incidence of dural tears during spinal endoscopy, the risk factors, and their appropriate management. Therefore, we have taken a different approach to studying the problem-a research method we have applied previously. ${ }^{1,3,5,15,16}$ A French group also used this approach in their study of currently practiced management of inciden- tal durotomy during lumbar surgery. ${ }^{9}$ We decided to pool data from a large number of surgeons via an online survey application. Our study presents the clinical results of 93 endoscopic spine surgeons who worked in various private or academic, singlespecialty, or multispecialty practice settings in 21 countries. These surgeons reported a surgery volume of 14150 lumbar endoscopies within the last year. They encountered 689 endoscopic dural tears during their entire careers, which ranged from 1-29 years, ${ }^{17-31}$ a time period in which they had performed a total of 64470 spinal endoscopies. In this study, we summarize the findings of our multicenter retrospective survey study.

\section{MATERIALS AND METHODS}

We solicited responses to an online survey (http:// www.typeform.com) we sent to 322 surgeons by email and via chat groups in social networks including WhatsApp and WeChat. Surgeons were asked to answer a variety of clinical questions regarding dural tears during lumbar endoscopy by choosing from several responses to multiple-choice questions. Responding spine surgeons were also allowed to free-text any information they thought was relevant. In addition, they were asked to provide some demographic information about themselves including their gender, age, country of residence, practice setting, type, and extent of postgraduate residency and fellowship training, as well as endoscopic surgery training (Table 1). To improve the survey completion rate and to minimize the impact of geographic bias, the survey questions were written by our team of authors. The survey ran from June 22, 2020, to August 20, 2020. We were blinded to the identity of the responding surgeons at all times. Upon completion of the survey, the responses were downloaded in an Excel file format and imported into the IBM SPSS (version 27; IBM Corp, Armonk, NY) statistical software package for further data analysis. Descriptive statistic measures were used to count responses and calculate the mean, range, and standard deviation as well as percentages. The $\chi^{2}$ statistic was used to determine the strength of association between factors. Missing responses were included for accurate percentage calculation and were listed at the top of each data table. Wherever applicable, a $P$ value of .05 or less was considered statistically significant, and a confidence interval of $95 \%$ was used for all statistical tests. 
Table 1. Demographic data of responding spine surgeons.

\begin{tabular}{|c|c|c|c|c|}
\hline & Frequency & Percentage & $\begin{array}{c}\text { Valid } \\
\text { Percentage }\end{array}$ & $\begin{array}{l}\text { Cumulative } \\
\text { Percentage }\end{array}$ \\
\hline \multicolumn{5}{|l|}{ What is your postgraduate training background? } \\
\hline Neurosurgeon & 26 & 28.0 & 28.0 & 28.0 \\
\hline Orthopedic surgeon & 65 & 69.9 & 69.9 & 97.8 \\
\hline Pain management & 1 & 1.1 & 1.1 & 98.9 \\
\hline Missing response & 1 & 1.1 & 1.1 & 100.0 \\
\hline Valid total & 93 & 100.0 & 100.0 & \\
\hline \multicolumn{5}{|l|}{ What is your training in minimally invasive and endoscopic spine surgery? } \\
\hline Formal MIS fellowship (6-12 mo) & 11 & 11.8 & 11.8 & 11.8 \\
\hline Formal MIS fellowship (6-12 mo), mentorship in spinal endoscopy (6-12 mo) & 3 & 3.2 & 3.2 & 15.1 \\
\hline I am self-taught in MIS & 4 & 4.3 & 4.3 & 19.4 \\
\hline I am self-taught in MIS, I am self-taught in spinal endoscopy & 2 & 2.2 & 2.2 & 21.5 \\
\hline I am self-taught in spinal endoscopy & 7 & 7.5 & 7.5 & 29.0 \\
\hline I completed MIS or endoscopy workshops & 20 & 21.5 & 21.5 & 50.5 \\
\hline I completed MIS or endoscopy workshops, formal MIS fellowship (6-12 mo) & 3 & 3.2 & 3.2 & 53.8 \\
\hline I prefer not to answer & 3 & 3.2 & 3.2 & 57.0 \\
\hline Mentorship in spinal endoscopy (6-12 mo) & 14 & 15.1 & 15.1 & 72.0 \\
\hline Spine-fellowship trained $(6-12 \mathrm{mo})$ & 3 & 3.2 & 3.2 & 75.3 \\
\hline Spine-fellowship trained (6-12 mo), formal MIS fellowship (6-12 mo) & 11 & 11.8 & 11.8 & 87.1 \\
\hline Spine-fellowship trained (6-12 months), I completed MIS or endoscopy workshop & 12 & 12.9 & 12.9 & 100.0 \\
\hline Total & 93 & 100.0 & 100.0 & \\
\hline \multicolumn{5}{|l|}{ What is your practice setting? } \\
\hline Hospital employed & 12 & 12.9 & 12.9 & 12.9 \\
\hline Private practice & 69 & 74.2 & 74.2 & 87.1 \\
\hline University & 12 & 12.9 & 12.9 & 100.0 \\
\hline Valid total & 93 & 100.0 & 100.0 & \\
\hline \multicolumn{5}{|l|}{ How many years have you practiced endoscopic spine surgery? } \\
\hline $1-5$ & 46 & 49.5 & 49.5 & 49.5 \\
\hline $11-15$ & 11 & 11.8 & 11.8 & 61.3 \\
\hline 16 or more & 10 & 10.8 & 10.8 & 72.0 \\
\hline $6-10$ & 26 & 28.0 & 28.0 & 100.0 \\
\hline Valid total & 93 & 100.0 & 100.0 & \\
\hline \multicolumn{5}{|l|}{ What is your age? } \\
\hline $25-34$ y & 5 & 5.4 & 5.4 & 5.4 \\
\hline $35-44 y$ & 43 & 46.2 & 46.2 & 51.6 \\
\hline $45-54 \mathrm{y}$ & 30 & 32.3 & 32.3 & 83.9 \\
\hline $55-64$ y & 10 & 10.8 & 10.8 & 94.6 \\
\hline 65 y or older & 5 & 5.4 & 5.4 & 100.0 \\
\hline Valid total & 93 & 100.0 & 100.0 & \\
\hline \multicolumn{5}{|l|}{ What is your country of residence? } \\
\hline Argentina & 2 & 2.2 & 2.2 & 2.2 \\
\hline Brazil & 32 & 34.4 & 34.4 & 36.6 \\
\hline Chile & 8 & 8.6 & 8.6 & 45.2 \\
\hline China & 11 & 11.8 & 11.8 & 57.0 \\
\hline Colombia & 6 & 6.5 & 6.5 & 63.4 \\
\hline Ecuador & 3 & 3.2 & 3.2 & 66.7 \\
\hline Germany & 1 & 1.1 & 1.1 & 67.7 \\
\hline Honduras & 1 & 1.1 & 1.1 & 68.8 \\
\hline India & 4 & 4.3 & 4.3 & 73.1 \\
\hline Indonesia & 2 & 2.2 & 2.2 & 75.3 \\
\hline Japan & 1 & 1.1 & 1.1 & 76.3 \\
\hline Mexico & 8 & 8.6 & 8.6 & 84.9 \\
\hline Panama & 1 & 1.1 & 1.1 & 86.0 \\
\hline Philippines & 4 & 4.3 & 4.3 & 90.3 \\
\hline Romania & 1 & 1.1 & 1.1 & 91.4 \\
\hline South Korea & 1 & 1.1 & 1.1 & 92.5 \\
\hline Taiwan & 1 & 1.1 & 1.1 & 93.5 \\
\hline Thailand & 2 & 2.2 & 2.2 & 95.7 \\
\hline United States of America & 3 & 3.2 & 3.2 & 98.9 \\
\hline Uruguay & 1 & 1.1 & 1.1 & 100.0 \\
\hline Valid total & 93 & 100.0 & 100.0 & \\
\hline
\end{tabular}

\section{RESULTS}

A total of 322 spine surgeons accessed the online survey on the typeform.com Web site; 93 submitted a valid survey recording. Thus, the completion rate was $28.9 \%$. The demographics of the responding surgeons is shown in Table 1. The majority of responding spine surgeons were residing in Brazil $(34.4 \% ; 32 / 93)$ and China $(11.8 \% ; 11 / 93)$. The remaining responding spine surgeons were from (in 
descending order) Chile $(8.6 \% ; 8 / 93)$, Mexico $(8.6 \% ; 8 / 93)$, Colombia $(6.5 \% ; 6 / 93)$, India $(4.3 \%$; $4 / 93)$, the Philippines $(4.3 \% ; 4 / 93)$, and other countries $(21.5 \%)$.

Of the 93 respondents, $28.0 \%$ (26/93) indicated that they were neurosurgeons, $69.9 \% \quad(65 / 93)$ designated that they were orthopedic surgeons, and the remaining respondent $(1.1 \% ; 1 / 93)$ was a pain management physician. The vast majority were male surgeons $(95.7 \%$; 89/93). Two respondents indicated that they were women $(2.2 \%)$, and another 2 respondents preferred not to indicate their gender $(2.2 \%)$. The majority of surgeons were from $35-44$ years of age $(46.2 \% ; 43 / 93)$ and from $45-54$ years of age $(32.3 \% ; 30 / 93)$. Regarding additional training, $39.8 \%$ (37/93) of respondents indicated they had completed a dedicated minimally invasive spinal surgery (MIS) or endoscopy workshop and used it as their primary spinal endoscopy training resource. Another 30.1\% (28/93) had completed a formal MIS spine fellowship of 6-12 months, whereas $26.9 \%$ (25/93) of responding spine surgeons had found a mentor as a training resource. Over a quarter of responding spine surgeons $(25.8 \%$; 24/93) were self-taught in MIS $(12.9 \%$; $12 / 93)$ or endoscopic $(12.9 \% ; 12 / 93)$ spine surgery. Three surgeons $(3.2 \%)$ preferred not to give details as to their MIS or endoscopy training. When asked about their practice setting, 72\% (67/93) of surgeons indicated they were in private practice. Another $29 \%$ (27/93) worked in a university setting, and $25.8 \%$ (24/93) were employed at hospitals. Regarding work experience, $29 \%$ (27/93) of responding surgeons indicated they had been in practice for 1115 years. Another $20.4 \%$ of surgeons indicated $6-10$ and 1-5 years of postgraduate clinical experience. As an approximate measure of proficiency in endoscopic spine surgery, we found that nearly half $(49.5 \% ; 46 / 93)$ of responding surgeons had been performing endoscopic spinal surgery for only 1-5 years, followed by a smaller group of spine surgeons $(28 \%$; 26/93) who indicated that their experience ranged from 6-10 years. Only the remaining $22.6 \%$ of spine surgeons had professional experience with spinal endoscopy over 10 years, and only $10.8 \%$ (10/ 93) had 16 years or more of such experience.

Endoscopic spine surgeons reported a case volume of 14150 lumbar endoscopies within the last year. Over their collective career years, they encountered 689 dural tears during the total of 64470 spinal endoscopies they had performed.
Most surgeons $(75.3 \% ; 70 / 93)$ had encountered an incidental durotomy during routine lumbar endoscopic surgery (Table 2). However, only 26.8\% (15/ 56) had considered the potential risk for a dural tear as a possible contraindication when selecting patients for endoscopic decompression surgery. The majority of endoscopic surgeons (77.4\%) reported negative connotations associated with incidental durotomy ranging from predictor of poor clinical outcome, need to stop surgery, need to convert to open surgery for repair, fear of spinal headaches, upset patient, fear of cerebrospinal fluid (CSF) fistula, trouble, complication, and "I hope I never have it"-just to name the most common concerns. Most responding surgeons were performing both the transforaminal $(71 \% ; 66 / 93)$ and interlaminar $(53.8 \%$; 50/93) approach, and a minority admitted to using the unilateral biportal (UBE) technique. Surgeons' preference was clearly with the posterolateral transforaminal endoscopy $(35.7 \%$; 20/56) even if they performed other approaches and methods (Table 3). Approximately one-third of surgeons admitted to exclusively performing either interlaminar $(28.6 \% ; 16 / 56)$ or transforaminal $(28.6 \% ; 16 / 56)$ surgery. Only 2 of the 56 surgeons responding to this question $(3.6 \%)$ were exclusively performing the UBE technique. The vast majority of surgeons reported higher risks with the interlaminar endoscopy $(92.4 \% ; 85 / 92$; Figure 1) versus $7.8 \%$ of surgeons who thought that posterolateral endoscopy via the transforaminal approach (Figure 2) was riskier. Actual tears were reported by $42.4 \%$ (39/92 surgeons) with the interlaminar approach, $37 \%$ (34/92) during stenosis endoscopy, and $20.7 \%$ (19/92) with the posterolateral transforaminal surgery.

When confronted with the prospect of an incidental dural tear during routine lumbar endoscopy, $44.6 \%$ (41/92) of surgeons admitted that they were not adequately trained and were searching for more instructional training (Table 4). Hands-on training for endoscopic dural closure was requested by $34.8 \%$ of respondents. Lack of adequate endoscopic instrumentation to deal with this challenging intraoperative complication was indicated by another $20.7 \%$ (19/92) of surgeons. Power burrs $(62 \% ; 57 / 92)$ were by far the most commonly used surgical tool that was involved in the creation of dural tears during routine lumbar endoscopy at a statistically significantly higher level in combination with the interlaminar approach $(P<.0001)$. Other 
Table 2. Frequency of incidental durotomy and decision-making.

1. Have you encountered an incidental durotomy during one of your lumbar endoscopic spinal surgeries?

( 93 of 93 surgeons answered this question)

2. What is your preferred lumbar endoscopic decompression technique? (93 of 93 surgeons answered this question) $53.8 \%$

3. When considering a patient for a fullendoscopic decompression, do you ever hesitate because of the possibility of a dural tear?

(56 of 93 surgeons answered this question)

$26.8 \%$

\begin{tabular}{|c|c|c|}
\hline $75.3 \%$ & Yes & 70 responses \\
\hline $24.7 \%$ & No & 23 responses \\
\hline
\end{tabular}

Transforaminal

66 responses

Interlaminar

50 responses

UBE (unilateral biportal)

7 responses

Never

18 responses

Probably yes

15 responses

$21.4 \%$

Neutral

12 responses

$14.3 \%$

Probably no

8 responses

$5.4 \%$

3 responses

Table 3. Incidental durotomy and full endoscopic approach.

1. Do you prefer posterolateral (foraminal) or interlaminar (discectomy/stenosis) endoscopy?

(56 of 93 surgeons answered this question)

2. Do you see a higher risk for durotomy in interlaminar or posterolateral endoscopic surgeries?

(92 of 93 surgeons answered this question)

3. During which full-endoscopic procedure have you encountered a dural tear(s)? (92 of 93 surgeons answered this question)

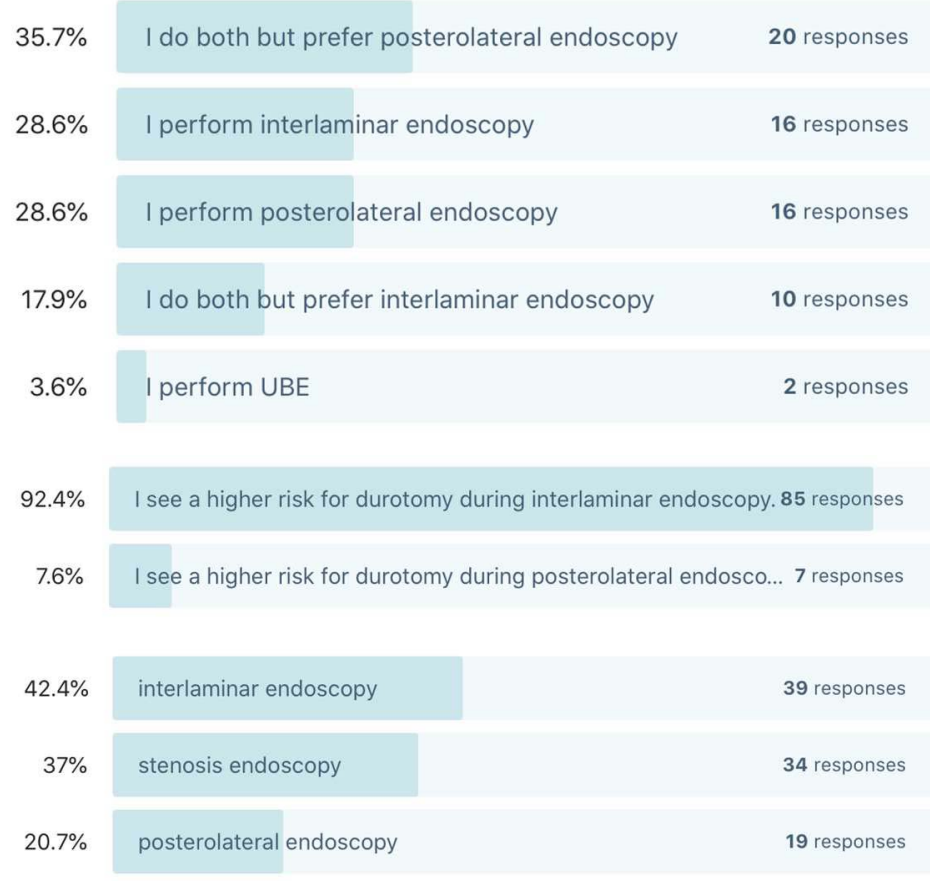




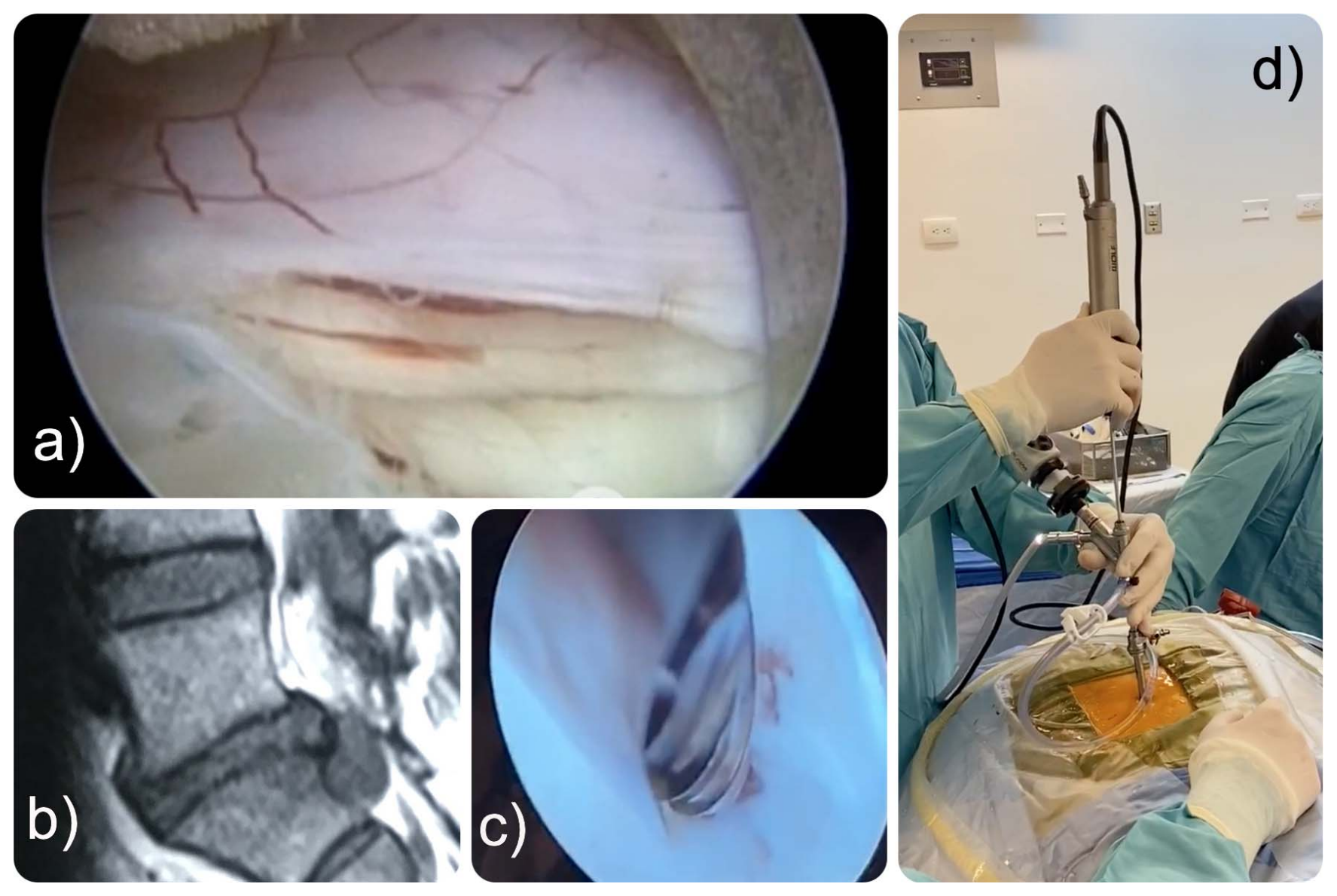

Figure 1. Shown is an exemplary case of (a) an incidental durotomy that the surgeon encountered in the posterior dural during interlaminar endoscopy (b) for a herniated disc at L5/S1 (c, d) with the application of a hooded power burr.

advanced cutting tools, such as reamers $(22.8 \% ; 21 /$ 92), trephines $(21.7 \% \% ; 20 / 92)$, and manual facet burrs $(17.4 \%$; 16/92) necessary for foraminal and lateral recess decompression, were involved in durotomy cases at nearly equal frequency. The use of endochisel instruments was associated with the lowest durotomy rate during lumbar endoscopy $(8.7 \% ; 8 / 92)$. The Kerrison rongeur was reported as the culprit by only 1 surgeon $(1.07 \% ; 1 / 93$; Figure 3). Seventy-eight percent $(78.3 \%$; 72/92) of surgeons indicated that they would deal with an incidental durotomy by applying mechanical compression with Gelfoam. Application of a blood patch was reported as useful by only 2 surgeons, who free-texted their recommendation. Another $12 \%$ of surgeons (11/92) had no contingency plan and did not know what to do in case of an incidental durotomy during lumbar endoscopy. Only 7.6\% (7/92) of surgeons anticipated that they would perform a conversion to open microsurgical decompression and dura repair. An even smaller proportion of respondents $(2.2 \% ; 2 / 92)$ requested specific endoscopic dura repair tools to deal with the problem.

Concerning actual reported durotomy numbers, participating survey surgeons had encountered 689 endoscopic dural tears in some 64470 spinal endoscopies to date. This yields an incidence rate for incidental durotomy with lumbar endoscopy at $1.07 \%$. Suppose one considers surgeons who reported more than 10 durotomies throughout their career as being outlier surgeons. In that case, it becomes apparent that 70\% (482) of 689 durotomies recorded in this study were accounted for by $20.4 \%$ (19) of the 93 surgeons who participated in this retrospective survey study. The adjusted durotomy rate if one were to exclude these outlier surgeons would be 0.32 . Of these 19 surgeons, 10 had fewer than 5 years of clinical experience with endoscopy, and the remaining 9 surgeons had more than 15 and up to 29 years of endoscopy experience.

Surgeons also reported that incidental durotomies were encountered significantly more often at a higher rate during endoscopic stenosis decompres- 


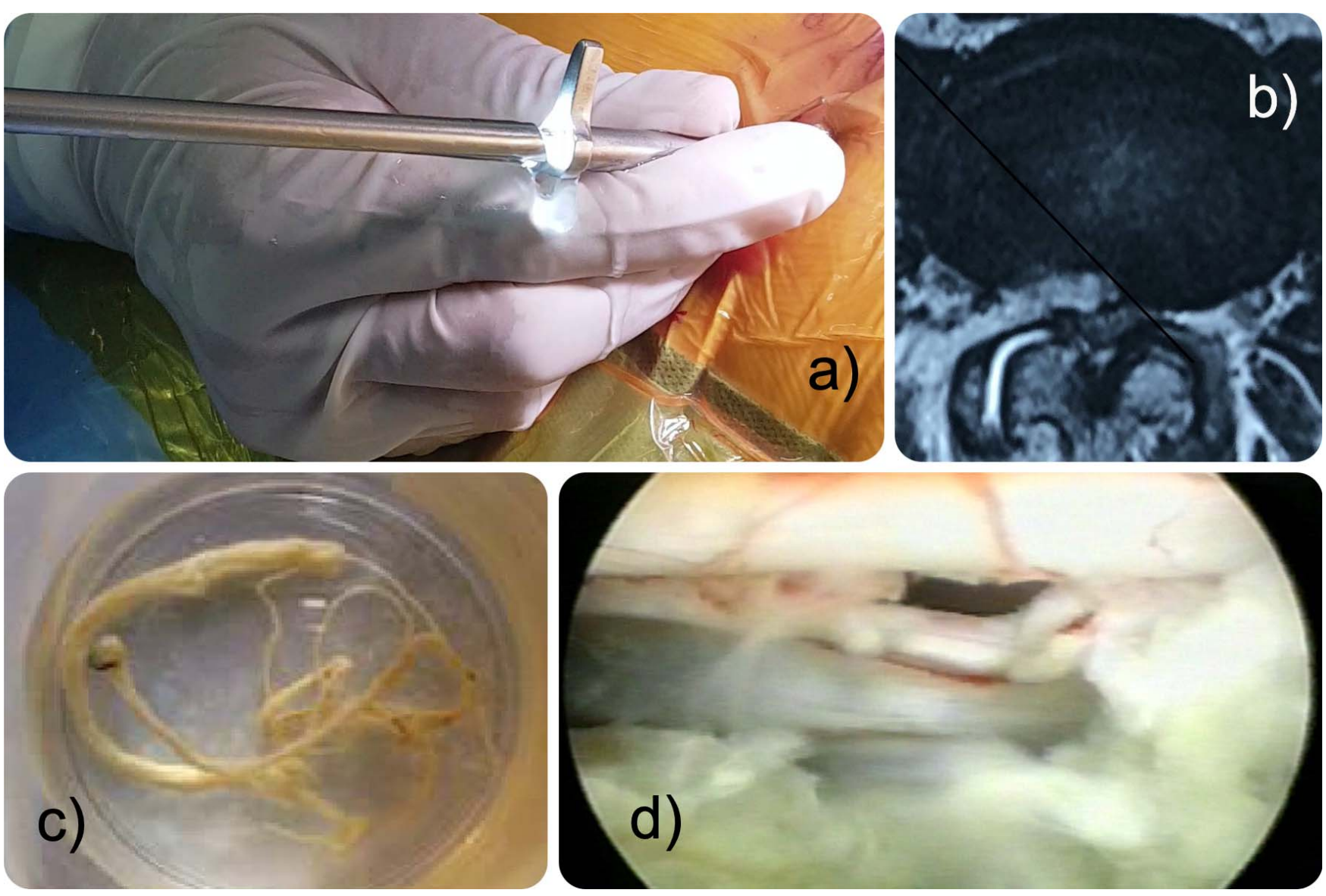

Figure 2. An exemplary case of an incidental durotomy is shown. (a) The tear was in the anterior dural sac during transforaminal endoscopy (b) for foraminal and lateral recess stenosis at L3-L4 with the application of a trephine. (c) A transected rootlet was removed from the decompression site. (d) The dural defect was created in the traversing nerve root.

sion $(54.8 \% ; 51 / 93 ; P<.0001)$, rather than during lumbar endoscopy performed for herniated disc (44.1\%; 41/93). Medium-sized dural tears (1-10 $\mathrm{mm}$ ) were the most common type of durotomy that occurred during lumbar endoscopic surgery $(52.2 \%$; 48/93). A small pinhole durotomy (less than $1 \mathrm{~mm}$ ) was the second most common type $(46.7 \%$; 43/93). Only 1 surgeon reported having 1 patient with a large dural tear (greater than $1 \mathrm{~cm}$ ). Rootlet herniations were seen by $46.2 \%$ (43/93) of responding surgeons. The posterior dural sac was the most common location for dural tears during an interlaminar approach $(57 \% ; 53 / 93)$. Traversing nerveroot injuries were most the second most common location of durotomy $(31.2 \% ; 29 / 93)$. Anterior dural sac $(23.7 \% ; 22 / 93)$ and exiting nerve-root injuries $(10.8 \% ; 10 / 93)$ were less common. Over half of the surgeons did not attempt any repair or closure $(52.2 \% ; 47 / 90)$. Forty percent $(36 / 90)$ used sealants. Only 7.8\% (7/90) of surgeons attempted an endoscopic repair or sutures $(11.1 \% ; 10 / 90)$. DuralSeal was the most commonly used brand of commercially available sealant $(42.7 \% ; 35 / 82)$. However, other sealants such as Tisseal (15.9\%; $13 / 82)$, Evicel $(2.4 \% ; 2 / 82)$, and no-brand sealants $(38 ; 32 / 82)$ were also used.

Postoperative management used by responding surgeons appeared less controversial. Of responding surgeons, $48.3 \%$ (43/89) recommended 48 hours of bed rest. Another $40.4 \%(36 / 89)$ of surgeons reported recommending less than 24 hours of bed rest. The long-term outcome was reported as unaffected by the majority of participating surgeons $(64 \% ; 57 / 89)$. Only $18 \%$ of surgeons reported that they had seen the development of a postoperative CSF fistula $(18 \% ; 16 / 89)$ with an incidental durotomy following lumbar endoscopy. However, when extrapolating total numbers of problem cases with CSF fistulas reported in this study from the entire patient base of 64470 lumbar endoscopic surgeries, the absolute incidence of CSF fistulas was only $0.025 \%(16 / 64470)$. Severe radiculopathy with dysesthesia was reported by $12.4 \%(11 / 89)$ of 
Table 4. Management of durotomy during full lumbar endoscopy.

1. Which of the following do you expect to lower the risk of a dural tear and/or help you be prepared for it?

( 92 of 93 surgeons answered this question)

2. What is your preferred endoscopic foraminoplasty tool? (92 of 93 surgeons answered this question)

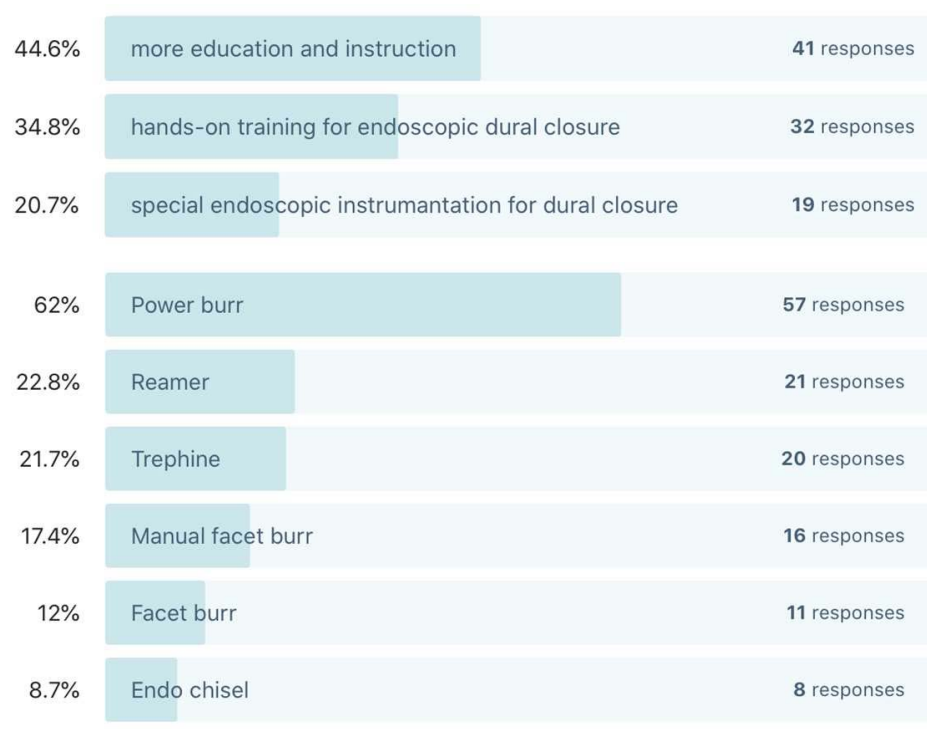

3. How do you plan to manage an incidental dural tear encountered during endoscopic spinal decompression? ( 92 of 93 surgeons answered this question)

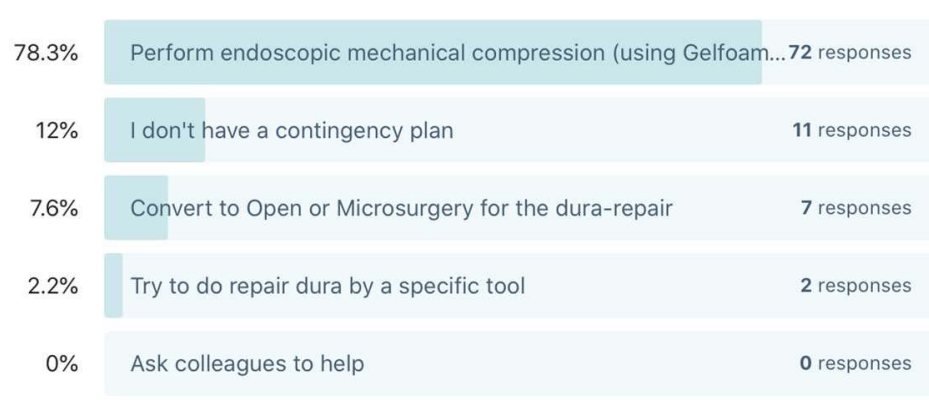

surgeons, sensory loss by 3.4\% (3/89), and motor weakness by $2.2 \%(2 / 89)$.

\section{DISCUSSION}

This retrospective study of 64470 lumbar endoscopies done by 93 surgeons in various private or academic, single-specialty, or multispecialty practice settings in 21 countries determined that 689 dural tears were encountered incidentally during lumbar spinal endoscopy. Therefore, the incidence of such durotomies was $1.07 \%$. The experience of the responding surgeons varied quite a bit, with nearly half of surgeons $(49.5 \%$; 46/93) reporting professional experience with endoscopy for only $1-5$ years versus smaller groups of expert spine surgeons reporting they had performed the procedure for over 10 and over 15 years $(22.6 \%$ and $10.8 \%$, respectively). This limited experience could certainly explain the discrepancy between the incidence of dural tears found in this study $(1.07 \%)$ and the much lower incidence recently reported by an extensive study of 1839 lumbar spinal endoscopy patients conducted over 9 years with a durotomy incidence of $0.1 \%$ (2/1839 patients) - a rate difference by 1 magnitude. ${ }^{4}$ Other authors ${ }^{32}$ from another endoscopic spine surgery center also reported the incidence of durotomy with the transforaminal endoscopic decompression well below $1 \%$-namely, $0.4 \%$. These differences in the incidence numbers also corroborate the concept that clinical outcomes with the lumbar spinal endoscopy are highly dependent on patient selection and surgeons' skill levels with the different endoscopic approaches they choose to use. With the increasing traction of the minimally invasive lumbar endoscopic surgery with patients and surgeons, a much larger number of operations are now being done by a larger percentage of practitioners with substantially less clinical experience and proficiency. Moreover, the interlaminar and $\mathrm{UBE}$ endoscopic decompression procedures conceptually resemble translaminar 


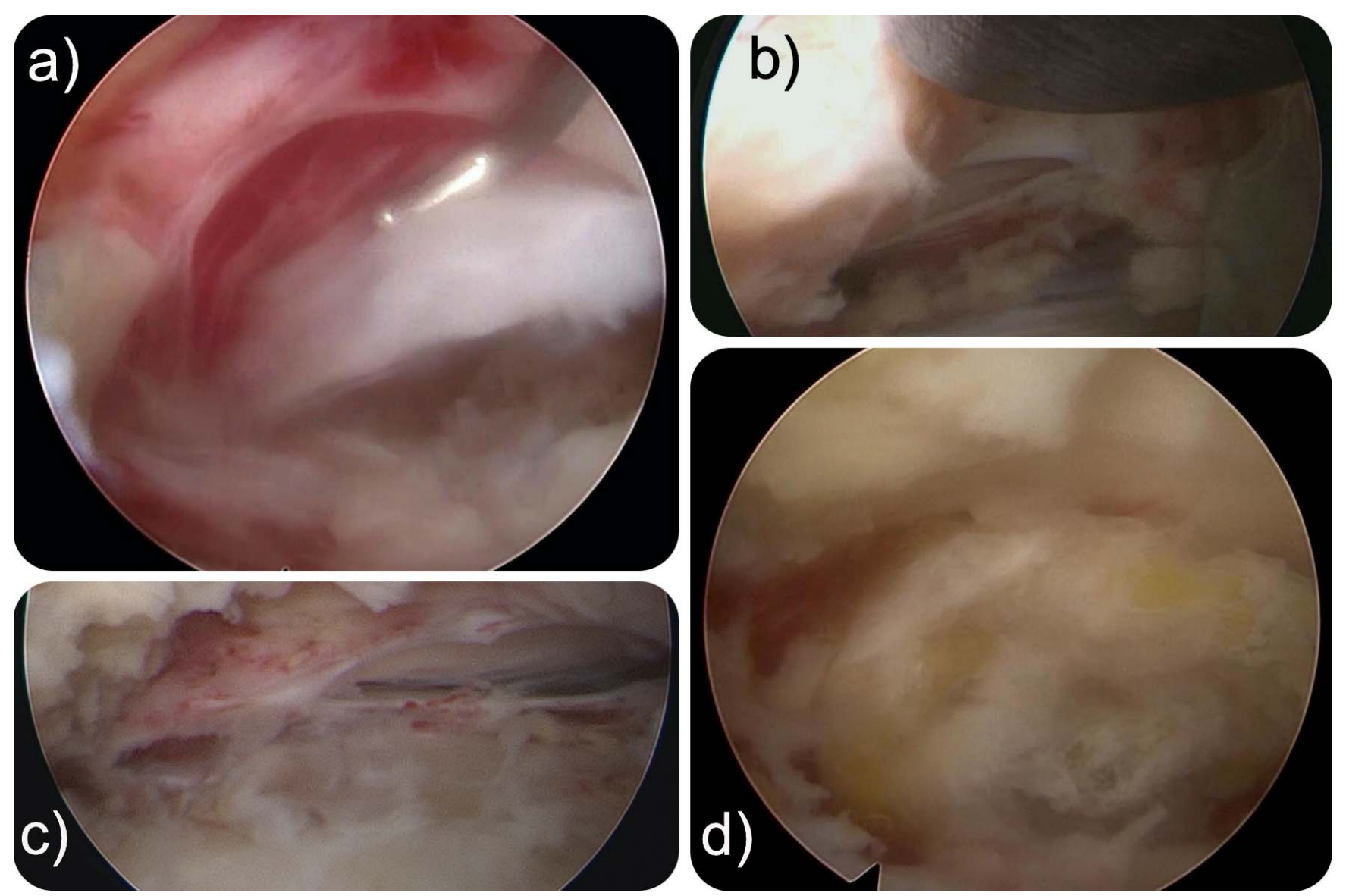

Figure 3. An exemplary case of an incidental durotomy is shown. (a) The tear caused a rootlet herniation and had occurred with (b) the use of the Kerrison rongeur during foraminoplasty by inadvertently "biting" the traversing nerve root. (c) It measured approximately $10 \mathrm{~mm}$ in length, and (d) the herniated rootlets were reduced before placing a Gelfoam patch.

open or microsurgical lumbar surgeries, only with the use of an irrigated videoendoscopic spine system through small incisions and a working channel rather than with an operating microscope or loupes through open or mini-open incisions or through tubular retractor exposures. Hence, one would expect the reported higher rate of durotomies with interlaminar ${ }^{30,33,34}$ and $\mathrm{UBE}^{12}$ techniques because the more fragile posterior dural $\mathrm{sac}^{35}$ is easily violated from the translaminar approach, particularly when power tools are involved. ${ }^{32}$

Incidental durotomy was recently evaluated by analyzing data on some 64431 patients from Sweden's National Quality Registry for Spine Surgery (SWESPINE) who underwent open lumbar surgery for lumbar disc herniation (LDH), lumbar spinal stenosis (LSS) without or with concomitant degenerative spondylolisthesis (DS). ${ }^{10}$ These authors found an overall incidence for durotomy of $5 \%$. For the LDH, LSS, and DS subgroups, incidence of durotomy was $2.8 \%, 6.5 \%$, and $6.5 \%$, respectively. The authors of the SWESPINE study also found that laminectomy was associated with a higher incidence of incidental durotomy than discectomy was $(P<.001)$. Additional confounding factors were previous spine surgery and increasing age $(P<.001) .{ }^{10}$ Our retrospective survey study results are more representative of real-world scenarios wherein patients and endoscopic spine surgeons can expect incidental durotomies to occur at a more realistic average rate of $1 \%$ or even higher, yet similar to those incidence rates reported with open surgery of $5 \%$ when the novice surgeons are just starting with the endoscopic decompression. Our analysis showed that 70\% (482/689) of all dural tears were reported by surgeons with fewer than 5 years or more than 15 years of experience. The higher durotomy numbers in the latter group of surgeons can be explained by their extensive endoscopic spine practice with thousands of cases spanning many years. The novice-surgeon group likely has a higher durotomy rate due to inexperience or lack of proficiency. 
Table 5. Characteristics and repair of durotomy during full lumbar endoscopy.

1. What was the surgical indication in your durotomy patients?

( 93 of 93 surgeons answered this question)

2. What was the size of the typical lumbar durotomy?

( 92 of 93 surgeons answered this question)

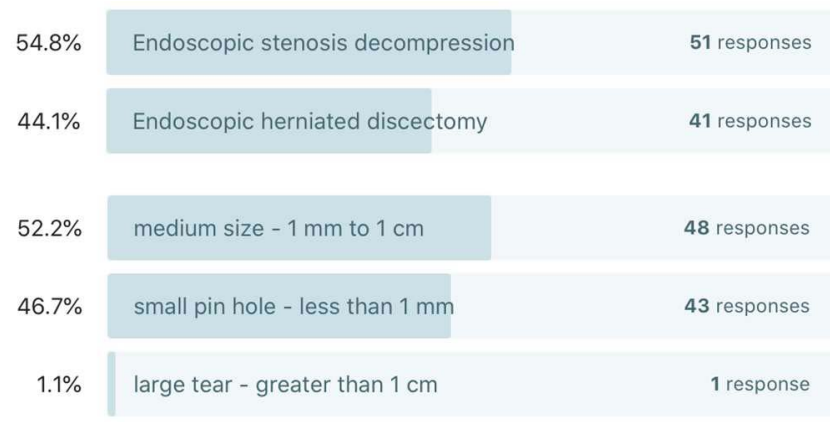

3. What was the predominant location of the dural tear?

(93 of 93 surgeons answered this question)

4. Was there a rootlet herniation? ( 93 of 93 surgeons answered this question)

5. How did you repair the durotomy? ( 90 of 93 surgeons answered this question)

6. What sealant did you use? ( 82 of 93 surgeons answered this question)
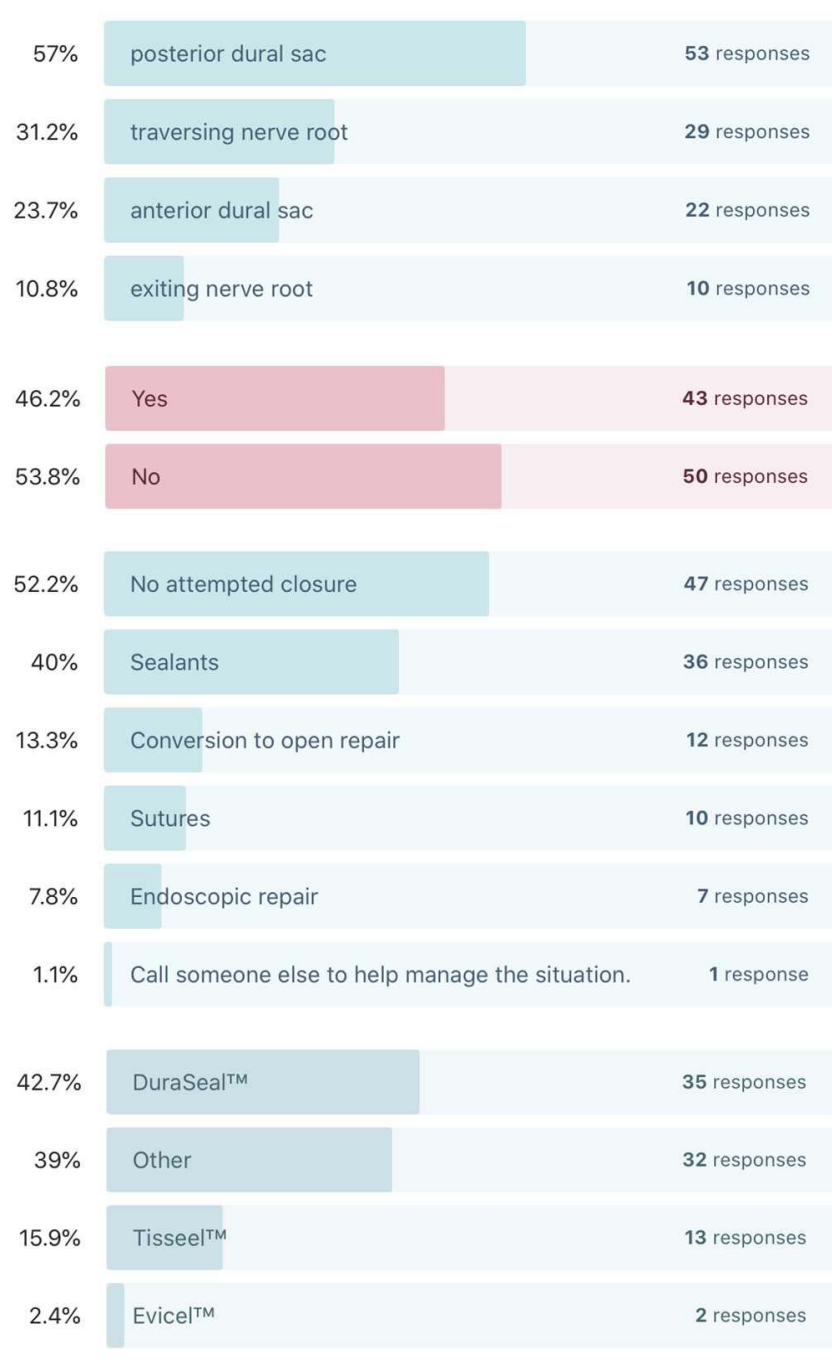

As with any new technology, formalized postgraduate training lags. This postgraduate training gap was also reflected in the responses given by participating surgeons regarding endoscopic specialty training. Whereas $30.1 \%$ had completed a formal MIS spine fellowship of 6-12 months, 39.8\% of surgeons indicated that they received their spinal endoscopy training in a short weekend workshop. Another $26.9 \%$ had found a mentor as a training resource. Nevertheless, over a quarter $(25.8 \%)$ of responding spine surgeons were self-taught, which highlights the fact that many of the younger surgeons $-46.2 \%$ of respondents were between the ages 35 and 44 years-had to figure out by 
Table 6. Postoperative management of durotomy and clinical outcomes.

1. What about bed rest?

( 89 of 93 surgeons answered this question)

2. Was the patient admitted to the hospital? ( 92 of 93 surgeons answered this question)

3. If applicable, what was the primary purpose of the hospital admission? (79 of 93 surgeons answered this question)

4. What was the clinical consequence of the dural tear?

( 89 of 93 surgeons answered this question)
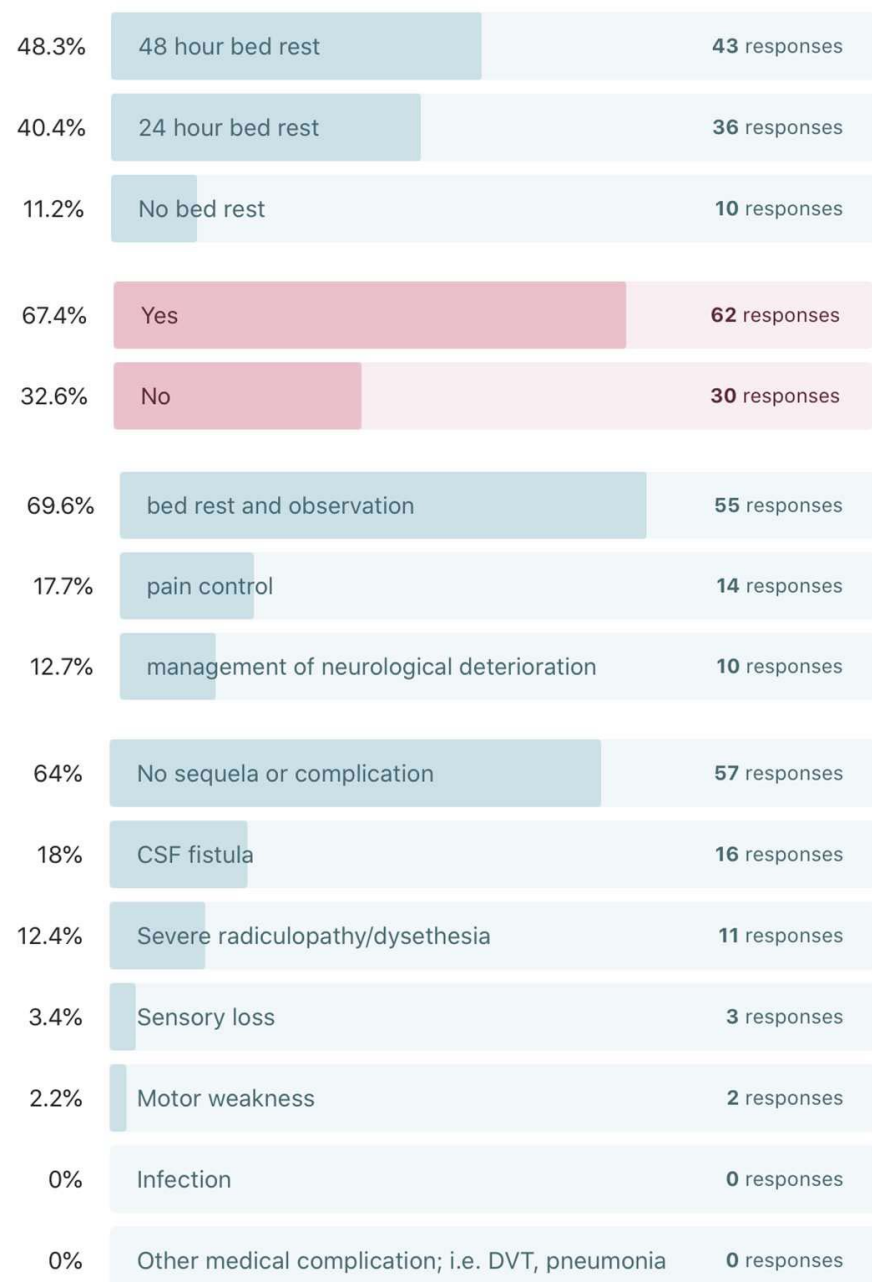

themselves how to manage intraoperative complications with the spinal endoscopy surgery. Some $44.6 \%$ of surgeons had no contingency plan and were looking for more training on managing this complication.

One of the most convincing findings of this study relates to the rising surgical case volume done with endoscopic minimally invasive techniques. Some 14150 of the 64470 captured by our team of authors were done within the last year. Whereas we had no way of determining a trend, it was apparent that the case volume by younger surgeons coming online is substantially increasing because $22 \%$ of the entire case volume was done just within the last year (as of the date of terminating the survey). Transforaminal endoscopic decompression surgery was the favorite among spine surgeons, with $71 \%$ indicating that they use it routinely. The interlam- inar approach was used by surgeons at a lower rate, with surgeons reporting that they used it in 53.8\% of their patients. Yet, it was associated with a higher rate of durotomies $(44.6 \%$ versus $37 \%$ ). UBE was of low relevance in this study but has been associated with dural tears as well. We were surprised by the high percentage of spine surgeons $(75.3 \%)$ who have had a dural tear. Many of us who authored this article are very experienced, key opinion leaders. We have performed the procedure well over 10 years and are accustomed to an incidence of dural tears well below $1 \%$. For example, the first author's (K.-U.L.) endoscopic spinal surgery career spans 14 years, and he has had only 2 dural tears. The senior author's (A.T.Y.) career spanned over 29 years, and he had only 4 dural tears from 1998 until his retirement in 2019. 
A factor contributing to the increased rate of durotomies during lumbar endoscopy that is less obvious than the increasing case volume and younger, less experienced surgeons relates to the substantial technological advances that have made their way into the operating room within the last 10 years. Many of them are miniaturized versions of power drills and burrs that have been adopted for use through the long and narrow inner working channels of contemporary lumbar foraminoscopes. Designs range from hooded to open drill bits and burrs used during the foraminoplasty and shavers that are particularly useful during the decompression's discectomy portion. Rigid power instruments are complemented by an array of designs with flexible and steerable tips that may pose additional risks for unrecognized durotomy because they may reach beyond the visual field of view provided by the endoscope. It was no surprise to us that surgeons reported power burrs $(62 \%)$ as by far the most common surgical tool involved in creating dural tears. Other advanced cutting tools, such as reamers $(22.8 \%)$, trephines $(21.7 \%)$, and manual facet burrs $(17.4 \%)$ necessary for foraminal and lateral recess decompression were also involved in durotomy cases but at a much lower frequency. The use of endochisel instruments was associated with the lowest durotomy rate $(8.7 \%)$. As expected, stenosis decompression $(54.8 \%)$ rather than endoscopic discectomy $(46.7 \%)$ was associated with a higher rate of durotomies because it involved more aggressive use of these mechanical power tools. Higher risks with the interlaminar endoscopy were reported by $92.4 \%$ of spine surgeons. Accordingly, durotomy incidence was higher with the interlaminar $(42.4 \%)$ than with the transforaminal approach $37 \%$. Mechanical compression with a sealant was preferred by $78.3 \%$ of surgeons. Application of a blood batch seemingly was considered by most surgeons an outdated concept. Only 2 surgeons reported it as being useful. Conversion to open surgery to repair the dural tear was deemed necessary by only $7.6 \%$ of respondents. Large dural tears with lumbar endoscopy were uncommon. Small tears of less than $1 \mathrm{~mm}(46.7 \%)$ and tears under $10 \mathrm{~mm}(52.2 \%)$ were the most common.

The postoperative management of incidental durotomies encountered during routine lumbar endoscopic surgery can be summarized as straightforward. On the basis of the collective data from 93 surgeons, it is evident that aggressive intraoperative management is not necessary. Most durotomies are very small, and only half of them involve a rootlet herniation. The latter often aid in sealing the dural defect, for which reason we assumed that CSF fistulas and persistent leaks would be uncommon. The long-term outcome was reported as unaffected by the majority of participating surgeons $(64 \% ; 57 /$ $89)$. Only $18 \%$ of surgeons reported a postoperative incidence of CSF fistula, a $12.4 \%$ incidence of severe radiculopathy with dysesthesia, a 3.4\% incidence of sensory loss, and a $2.2 \%$ incidence of motor. However, the true incidence of dysesthesia in patients with durotomies is unknown and was more likely due to dorsal root ganglion irritation. Most patients' tears were successfully managed with an application of a sealant and a short period of 24-48 hours of postoperative bed rest. Spinal headaches are often feared by spinal surgeons as an annoying sensation to patients that could prompt readmission, particularly if the surgery is done in an outpatient ambulatory surgery center setting. Therefore, we recommend including the discussion of dural tears in the preoperative teaching process as much as postoperative nerve root irritations, which are by far more common.

The same bias limitations plagued this study as any other retrospective and survey study. Our response rate of $28.9 \%$ is on par with previously reported online surveys. The average response rates for an in-person survey has been reported at 57\%, mail survey at $50 \%$, email survey at $30 \%$, online survey at $29 \%$, telephone survey at $18 \%$, and an inapp survey at $13 \%$, rendering an overall average survey response rate of $33 \% .^{36-42}$ Responses were blinded, and we had no information about the identity of the responding spine surgeons, limiting the impact of intuition and hindsight bias among the investigators. The effect of nonresponse bias due to the low response rate may have improved survey accuracy and was of no concern to our team of authors because low response rates in the $20 \%$ range have been related to more-accurate measurements more than surveys with a $60 \%-70 \%$ response rate because the missing data are not random. ${ }^{43}$ Additional limitations may have arisen from geographic bias in that the digital communication used in this survey study could have obliterated existing geographic diversity and various cultural perspectives of responding to spine surgeons. We assumed a negligible impact of geographic bias factors because statistical testing did not show any effect of 
geographic or cultural factors in the collected data. Instead, we were cautious not to generalize this retrospective survey's findings in the context of our preconceived notions of endoscopic dural tears to counter the homogenizing effect of the digital data acquisition across multiple geographical and cultural boundaries. Hindsight and recall bias by the responding surgeons may have been the most relevant limitations of this study because the information presented herein was not based on a patient registry but on the surgeons' ability to recall patient-specific details surrounding durotomies and to resist the influence of clinical outcome knowledge that is anchored in reconstructive memory (hindsight bias). ${ }^{43} \mathrm{We}$ recognized that their personal experience with dural tears during lumbar endoscopy was quite different and acknowledged the genuinely alternative insights from other surgeons. A $1 \%$ incidence of incidental dural tears is higher than they were accustomed to $(0.1 \%)$ and is likely more realistic.

\section{CONCLUSIONS}

There are a few solid take-home points from this retrospective survey study among busy endoscopic spine surgeons. The incidence of dural tears with lumbar endoscopy was about $1 \%$. It was higher than previously reported, was highly associated with the use of power drills and burrs, and was more common with the interlaminar than the transforaminal approach. Stenosis decompression that typically requires the more aggressive use of these power instruments had a slightly higher incidence of dural tears than endoscopic decompression for a herniated disc. Most dural tears were small and could be successfully managed with mechanical compression with Gelfoam and sealants. Two-thirds of endoscopic spine surgeons reported an entirely uneventful postoperative course in their patients after an incidental dural tear. The remaining onethird of surgeons had seen problems directly related to durotomy in their patients' postoperative course but at a low overall incidence including persistent CSF leak via a fistula $(0.025 \%)$, severe radiculopathy with dysesthesias $(12.4 \%)$, sensory loss $(3.4 \%)$, and motor function $(2.2 \%)$ loss. Considering that CSF leaks and dysesthesias are ultimately either adequately managed or self-limiting, the overall negative effect of incidental durotomy is less consequential as viewed by most surgeons who responded to this survey. However, it should not be trivialized. Every surgeon should have a contingency plan in place to have the team in the operating room be prepared to adequately manage this rare complication. Patients should be educated preoperatively and reassured after satisfactory management of durotomy if it occurred during surgery.

\section{REFERENCES}

1. Kim JS, Yeung A, Lokanath YK, et al. Is Asia truly a hotspot of contemporary minimally invasive and endoscopic spinal surgery? J Spine Surg. 2020;6:S224-S236.

2. Lin GX, Kotheeranurak V, Mahatthanatrakul A, et al. Worldwide research productivity in the field of full-endoscopic spine surgery: a bibliometric study. Eur Spine J. 2020;29:153160.

3. Lewandrowski KU, Soriano-Sanchez JA, Zhang X, et al. Regional variations in acceptance, and utilization of minimally invasive spinal surgery techniques among spine surgeons: results of a global survey. J Spine Surg. 2020;6:S260-S274.

4. Lewandrowski KU. Incidence, management, and cost of complications after transforaminal endoscopic decompression surgery for lumbar foraminal and lateral recess stenosis: a value proposition for outpatient ambulatory surgery. Int $J$ Spine Surg. 2019;13:53-67.

5. Lewandrowski KU, Soriano-Sanchez JA, Zhang X, et al. Surgeon training and clinical implementation of spinal endoscopy in routine practice: results of a global survey. J Spine Surg. 2020;6:S237-S248.

6. Teli M, Lovi A, Brayda-Bruno M, et al. Higher risk of dural tears and recurrent herniation with lumbar microendoscopic discectomy. Eur Spine J. 2010;19:443-450.

7. Oertel JM, Burkhardt BW. Full endoscopic treatment of dural tears in lumbar spine surgery. Eur Spine J. 2017;26:24962503.

8. Ahn Y, Lee HY, Lee SH, et al. Dural tears in percutaneous endoscopic lumbar discectomy. Eur Spine $J$. 2011;20:58-64.

9. d'Astorg H, Szadkowski M, Vieira TD, et al. Management of incidental durotomy: results from a nationwide survey conducted by the French Society of Spine Surgery. World Neurosurg. 2020;S1878-8750(20):31642-31649.

10. Strömqvist F, Sigmundsson FG, Strömqvist B, et al. Incidental durotomy in degenerative lumbar spine surgery-a register study of 64,431 operations. Spine J. 2019;19:624-630.

11. Muller SJ, Burkhardt BW, Oertel JM. Management of dural tears in endoscopic lumbar spinal surgery: a review of the literature. World Neurosurg. 2018;119:494-499.

12. Park HJ, Kim SK, Lee SC, et al. Dural tears in percutaneous biportal endoscopic spine surgery: anatomical location and management. World Neurosurg. 2020;136:e578e585.

13. Takenaka S, Makino T, Sakai Y, et al. Dural tear is associated with an increased rate of other perioperative complications in primary lumbar spine surgery for degenerative diseases. Medicine (Baltimore). 2019;98(1):e13970. doi:10.1097 MD.0000000000013970

14. Shin JK, Youn MS, Seong YJ, et al. Iatrogenic dural tear in endoscopic lumbar spinal surgery: full endoscopic dural suture repair (Youn's technique). Eur Spine J. 2018;27:544-548. 
15. Lewandrowski KU, Soriano-Sanchez JA, Zhang X, et al. Surgeon motivation, and obstacles to the implementation of minimally invasive spinal surgery techniques. J Spine Surg. 2020;6:S249-S259.

16. Lewandrowski KU, Zhang X, Ramirez Leon JF, et al. Lumbar vacuum disc, vertical instability, standalone endoscopic interbody fusion, and other treatments: an opinion based survey among minimally invasive spinal surgeons. J Spine Surg. 2020;6:S165-S178.

17. Yeung A, Roberts A, Zhu L, et al. Treatment of soft tissue and bony spinal stenosis by a visualized endoscopic transforaminal technique under local anesthesia. Neurospine. 2019;16:52-62.

18. de Carvalho PST, Ramos MRF, da Silva Meireles AC, et al. Feasibility of using intraoperative neuromonitoring in the prophylaxis of dysesthesia in transforaminal endoscopic discectomies of the lumbar spine. Brain Sci. 2020;10(8):pii: brainsci10080522. doi:10.3390/brainsci10080522

19. Dowling A, Barcenas JGH, Lewandrowski KU. Transforaminal endoscopic decompression and uninstrumented allograft lumbar interbody fusion: a feasibility study in patients with end-stage vacuum degenerative disc disease. Clin Neurol Neurosurg. 2020;196:106002. doi:10.1016/j.clineuro.2020. 106002

20. Dowling A, Lewandrowski KU, da Silva FHP, et al. Patient selection protocols for endoscopic transforaminal, interlaminar, and translaminar decompression of lumbar spinal stenosis. J Spine Surg. 2020;6:S120-S132.

21. Hellinger S, Lewandrowski KU. Clinical outcomes with endoscopic resection of lumbar extradural cysts. J Spine Surg. 2020;6:S133-S144.

22. Ramirez Leon JF, Ardila AS, Rugeles Ortiz JG, et al. Standalone lordotic endoscopic wedge lumbar interbody fusion (LEW-LIF) with a threaded cylindrical peek cage: report of two cases. J Spine Surg. 2020;6:S275-S284.

23. Yeung A, Lewandrowski KU. Five-year clinical outcomes with endoscopic transforaminal foraminoplasty for symptomatic degenerative conditions of the lumbar spine: a comparative study of inside-out versus outside-in techniques. $J$ Spine Surg. 2020;6:S66-S83.

24. Yeung A, Lewandrowski KU. Early and staged endoscopic management of common pain generators in the spine. J Spine Surg. 2020;6:S1-S5.

25. Yuan H, Zhang X, Zhang LM, et al. Comparative study of curative effect of spinal endoscopic surgery and anterior cervical decompression for cervical spondylotic myelopathy. $J$ Spine Surg. 2020;6:S186-S196.

26. Lewandrowski KU, de Carvalho PST, Calderaro AL, et al. Outcomes with transforaminal endoscopic versus percutaneous laser decompression for contained lumbar herniated disc: a survival analysis of treatment benefit. J Spine Surg. 2020;6:S84-S99.

27. Lewandrowski KU, Dowling A, Calderaro AL, et al. Dysesthesia due to irritation of the dorsal root ganglion following lumbar transforaminal endoscopy: analysis of frequency and contributing factors. Clin Neurol Neurosurg. 2020;197:106073. doi:10.1016/j.clineuro.2020.106073

28. Lewandrowski KU, Dowling A, de Carvalho P, et al. Indication and contraindication of endoscopic transforaminal lumbar decompression. World Neurosurg. 2020. 2020;pii: S1878-8750(20)30547-7. doi:10.1016/j.wneu.2020.03.076
29. Liu J, Zhang H, Zhang X, et al. Percutaneous endoscopic decompression for lumbar spinal stenosis: protocol for a systematic review and network meta-analysis. Medicine (Baltimore). 2019;98(20):e15635. doi:10.1097/MD.0000000000015635

30. Xin Z, Huang P, Zheng G, et al. Using a percutaneous spinal endoscopy unilateral posterior interlaminar approach to perform bilateral decompression for patients with lumbar lateral recess stenosis. Asian J Surg. 2019; pii: S10159584(19)30789-4. doi:10.1016/j.asjsur.2019.08.010

31. Xiu P, Zhang X. Endoscopic spine surgery in China: its evolution, flourishment, and future opportunity for advances. $J$ Spine Surg. 2019:S49-S53.

32. Telfeian AE, Shen J, Ali R, et al. Incidence and implications of incidental durotomy in transforaminal endoscopic spine surgery: case series. World Neurosurg. 2020;134:e951-e955.

33. Yin J, Jiang Y, Nong L. Transforaminal approach versus interlaminar approach: a meta-analysis of operative complication of percutaneous endoscopic lumbar discectomy. Medicine (Baltimore). 2020;99(25):e20709. doi:10.1097/MD. 0000000000020709

34. Wasinpongwanich K, Pongpirul K, Myat Lwin KM, et al. Full-endoscopic interlaminar lumbar discectomy: retrospective review of clinical results and complications in 545 international patients. World Neurosurg. 2019;pii: S18788750(19)32007-8. doi:10.1016/j.wneu.2019.07.101

35. Wen $\mathrm{H}$, Wang $\mathrm{X}$, Liao $\mathrm{W}$, et al. Effective range of percutaneous posterior full-endoscopic paramedian cervical disc herniation discectomy and indications for patient selection. Biomed Res Int. 2017;2017:3610385. Published online October 26, 2017. doi:10.1155/2017/3610385.

36.Todd AL, Porter M, Williamson JL, et al. Pre-notification letter type and response rate to a postal survey among women who have recently given birth. BMC Med Res Methodol. 2015;15:104. doi:10.1186/s12874-015-0097-837.

37. Millar MM. Improving response to web and mixed-mode surveys. https://www.academic.oup.com/poq/article/75/2/249/ 1860211. Accessed September 22, 2019.

38. 12 Mind-blowing employee survey statistics. http://www. officevibe.com/blog/employee-surveys-infographic. Accessed February 13, 2021.

39. Mobile survey response rates: averages and benchmarks by app category. http://www.apptentive.com/blog/2016/10/04/ mobile-survey-response-rates/. Accessed September 22, 2019.

40. What is an acceptable survey response rate? http:// socialnorms.org/what-is-an-acceptable-survey-response-rate/. Accessed September 22, 2019.

41. The complete guide to acceptable survey response rates. https://www.genroe.com/blog/acceptable-survey-response-rate2/11504. Accessed September 22, 2019.

42. What low response rates mean for telephone surveys. http://www.pewresearch.org/2017/05/15/what-low-responserates-mean-for-telephone-surveys/. Accessed September 22, 2019.

43. Henriksen K, Kaplan H. Hindsight bias, outcome knowledge, and adaptive learning. Qual Saf Health Care. 2003;12(suppl 2):ii46-ii50. doi:10.1136/qhc.12.suppl_2.ii46

Disclosures and COI: Jorge Felipe Ramírez León, MD, is a shareholder and president of the 
board of directors, Ortomac, Colombia, and a consultant with Elliquence, USA. No other authors received funding for this study or declared conflicts of interest.

Corresponding Author: Kai-Uwe Lewandrowski, MD, Center for Advanced Spine Care of Southern Arizona, 4787 East Camp Lowell Dr,
Tucson AZ 85712. Email: Business@tucsonspine. com.

Published 16 April 2021

This manuscript is generously published free of charge by ISASS, the International Society for the Advancement of Spine Surgery. Copyright (C) 2021 ISASS. To see more or order reprints or permissions, see http://ijssurgery.com. 